\title{
BMJ Open Systematic review and meta-analysis: Tai Chi for preventing falls in older adults
}

\author{
Zhi-Guan Huang, ${ }^{1}$ Yun-Hui Feng, ${ }^{2}$ Yu-He Li, ${ }^{1}$ Chang-Sheng Lv ${ }^{1}$
}

To cite: Huang Z-G, Feng Y$\mathrm{H}$, Li Y-H, et al. Systematic review and meta-analysis: Tai Chi for preventing falls in older adults. BMJ Open 2017;7:e013661.

doi:10.1136/bmjopen-2016013661

- Prepublication history and additional material is available. To view please visit the journal (http://dx.doi.org/ 10.1136/bmjopen-2016013661).

Received 1 August 2016 Revised 21 November 2016 Accepted 9 December 2016

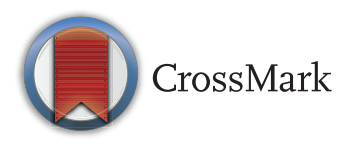

${ }^{1}$ Engineering Research Center for Sports Assistive Devices Design, Guangzhou Sport University, Guangzhou, People's Republic of China ${ }^{2}$ Department of Physical Education, School of Physical Education and Sports Science, Guangzhou University, Guangzhou, People's Republic of China

Correspondence to Professor Yu-He Li; yuheli2000@163.com Professor Yun-Hui Feng; 932832207@qq.com

\section{ABSTRACT}

Objective: It remains unclear whether Tai $\mathrm{Chi}$ is effective for preventing falls in older adults. We undertook this systematic review to evaluate the preventive effect of Tai Chi by updating the latest trial evidence.

Design: Systematic review and meta-analysis. Methods: The Cochrane Library, MEDLINE and EMBASE were searched up to February 2016 to identify randomised trials evaluating Tai Chi for preventing falls in older adults. We evaluated the risk of bias of included trials using the Cochrane Collaboration's tool. Results were combined using random effects meta-analysis.

Outcome measures: Number of fallers and rate of falls.

Results: 18 trials with 3824 participants were included. The Tai Chi group was associated with significantly lower chance of falling at least once (risk ratio (RR) $0.80,95 \% \mathrm{Cl} 0.72$ to 0.88 ) and rate of falls (incidence rate ratio (IRR) $0.69,95 \% \mathrm{Cl} 0.60$ to 0.80 ) than the control group. Subgroup analyses suggested that the preventive effect was likely to increase with exercise frequency (number of fallers: $p=0.001$; rate of falls: $p=0.007$ ) and Yang style Tai Chi was likely to be more effective than Sun style Tai Chi (number of fallers: $p=0.01$; rate of falls: $p=0.001$ ). The results might be influenced by publication bias as the funnel plots showed asymmetry. Sensitivity analyses by sample size, risk of bias and comorbidity showed no major influence on the primary results.

Conclusions: Tai Chi is effective for preventing falls in older adults. The preventive effect is likely to increase with exercise frequency and Yang style Tai Chi seems to be more effective than Sun style Tai Chi.

\section{INTRODUCTION}

Falls are common among older adults and are one of the major threats to their health. The incidence of falls varies with living status and increases with age; in general population, $30-40 \%$ people over 65 years fall every year worldwide, increasing to $\sim 50 \%$ among people aged 80 years and older. ${ }^{1}{ }^{2}$ Falls in older people are associated with considerable subsequent decline in functional status and increase in nursing home admissions and

\section{Strengths and limitations of this study}

- This study is, to date, the most comprehensive systematic review evaluating Tai Chi for preventing falls in older adults. A number of recently published trials were included, which improved the precision of the estimated effects and enabled us to investigate various influential factors such as Tai Chi style and frequency.

- Our confidence in the findings is further increased by significant dose-response effect, stable sensitivity analyses and stable analyses by adjusting for publication bias.

- The findings are likely to be influenced due to the bias in some original trials.

- The estimated preventive effect of Tai Chi may be overestimated due to publication bias.

medical resources consumptions. ${ }^{3} \quad 4$ Fall-related complications are the leading cause of unintentional injury deaths in people over 65 and the fifth leading cause of death. ${ }^{5} 6$

A number of interventions, including adaptation and modification of home environment, exercise, medication modification and vitamin $\mathrm{D}$ supplementation, have been applied for preventing falls. ${ }^{7-9}$ Tai Chi is a traditional systematic calisthenics exercise widely practiced in China. Tai Chi has been shown to be effective in improving balance, proprioception, muscle strength and endurance, ${ }^{10}{ }^{11}$ therefore it may be beneficial for preventing falls among the elderly. To date, the preventive effect of Tai Chi has been evaluated by a number of randomised controlled trials (RCTs); however, their findings were inconsistent. ${ }^{12-15}$ Although some authors have synthesised the results of the related original trials, ${ }^{16-18}$ these secondary studies might miss some trials and some recently published RCTs were not included. Moreover, the preventive effect of Tai Chi may vary with Tai Chi style, exercise dose, exercise duration and time of follow-up, but the preventive effect in these subgroups was 
unclear. The primary aim of this study was to evaluate the effect of Tai Chi for preventing falls in older adults by updating the latest trial evidence. The secondary aim was to explore the association between the effectiveness and potential influential factors including Tai Chi frequency, total exercise time, follow-up time, falling risk at enrolment and type of Tai Chi.

\section{METHODS}

\section{Criteria for study inclusion}

This systematic review included RCTs evaluating the effect of Tai Chi exercise in people aged over 60 years. A trial was eligible if the age of participants was not limited, but the average age was over 65 years. The participants in the control group may receive usual care, stretching or other low-level exercises, education or standard lifestyle modification. The follow-up time of eligible study should be 4 weeks or longer. Additionally, eligible studies should report at least one study outcome of this systematic review. The primary outcome for this study was the number of fallers (the participants who fell at least once). Rate of falls (the number of falls per person-year) was considered as the secondary outcome.

\section{Literature search and study selection}

An electronic search of Cochrane Library (Issue 2, 2016), MEDLINE (1966 to 1 February 2016) and EMBASE (1984 to 1 February 2016) was performed to identify potentially eligible trials. The search strategy included terms for Tai Chi, falls and a filter for RCTs using the following combined text and MeSH terms: 'Tai Chi', 'falls', 'accidents', and 'randomized controlled trial' (for full search strategy, see online supplementary table S1). All searches were restricted to human studies, and there was no limitation on language and publication status. We searched the MetaRegister of Controlled Trials and the WHO International Clinical Trials Registry Platform for ongoing studies. The reference lists of the included studies and related review articles were screened to identify additional studies.

We input the records from electronic databases into database management software, and the duplicate citations were removed. Two authors (Z-GH and Y-HF) then independently evaluated the eligibility of the remaining citations by examining the titles, abstracts and full articles sequentially. Discrepancies were resolved by discussion.

\section{Data extraction and risk of bias}

Two investigators (Z-GH and C-SL) independently extracted data from eligible studies and evaluated the risk of bias; the investigators were not blinded. Disagreements were resolved by discussion between the two investigators until a consensus was achieved. The extracted data included study characteristics (ie, title, authors, location, publication date, number of participants, setting and study duration), patient characteristics (ie, age, gender, previous falling history, marriage, education, living status, drinking, smoking, overall health status, use of walking aid and comorbidity), interventions and comparisons (type of Tai Chi, exercise intensity, duration and frequency), outcomes (number of fallers and rate of falls) and study methods (study design, random sequence generation, allocation concealment, methods for dealing with missing data, selective reporting and other methodological issues). We contacted the authors of original studies to collect missing information when necessary. The risk of bias of included RCTs was evaluated using the Cochrane Collaboration's tool for assessing risk of bias. ${ }^{19}$

\section{Data analysis}

We pooled data with a random effects model which accounts for within and between-study variability to provide more conservative estimates. RR, together with the corresponding $95 \% \mathrm{CI}$, was used as the summary effect measure for the number of fallers. We used IRR to compare the rate of falls.

We evaluated the heterogeneity among studies with the Q-test and the $\mathrm{I}^{2}$-index statistic. A value for $\mathrm{I}^{2}>50 \%$ accompanied by $\mathrm{p}<0.10$ for the $\mathrm{Q}$-test was regarded as being indicative of moderate to high level of heterogeneity. ${ }^{19}$ We carried out subgroup analyses to evaluate the estimated effect in specific subgroups and to evaluate potential interactions. Subgroup analyses were carried out according to Tai Chi frequency (once, twice, three times and more than three times per week), total Tai Chi exercise time ( $\leq 30$ hours, $>30$ and $\leq 60$ hours and $>60$ hours), time of follow-up ( $>1$ and $\leq 3$ months, $>3$ and $\leq 6$ months, and $>6$ months), falling risk at enrolment (low and high) and type of Tai Chi exercise (Yang style Tai Chi and Sun style Tai Chi).

For each outcome, we used funnel plot to examine the publication bias if the number of original trials included in the meta-analysis was $\geq 10$. The symmetry of the funnel plots was assessed by Egger's test. ${ }^{19}{ }^{20}$ When the funnel plot showed asymmetry, we used trim and fill method to adjust for publication bias in meta-analysis. ${ }^{21}$ Moreover, we undertook sensitivity analyses according to sample size (excluding studies with sample size $<100$ participants), risk of bias (excluding studies with high risk of bias in one or more domains, or with unclear risk of bias in more than three domains, according to the assessment results in online supplementary table S2) and comorbidity (excluding studies which included patients with stroke and Parkinson's disease). Data analyses were performed using Cochrane Collaboration review manager software (RevMan V.5.1) and STATA V.12 (StataCorp, College Station, Texas, USA).

\section{RESULTS}

\section{Study characteristics and risk of bias}

The electronic search and search for additional resources totally identified 227 potentially eligible citations, of which 177 were excluded after removing duplicates and screening the titles and abstracts. The full 
texts of the 50 remaining records were screened, and finally, 18 studies including 3824 participants were included (figure 1). ${ }^{12-15} 22-35^{\circ}$

Table 1 presents the characteristics of included studies. Seven included studies were carried out in the USA, $^{14} 152227293134$ three in China, ${ }^{13} 2435$ two in Taiwan, $^{25} 26$ two in Australia, ${ }^{23} 33$ two in Netherlands, $^{12} 28$ one in New Zealand ${ }^{30}$ and one in Canada. ${ }^{32}$ Most studies recruited participants from the community except for the study by Gao et $a l,{ }^{24}$ which recruited participants from hospital and community. Three studies were undertaken in frail and prefrail older adults, ${ }^{12} 3234$ two studies in patients with stroke, ${ }^{15} 31$ two in patients with Parkinson's disease, ${ }^{24} 27$ one in postmenopausal women with osteopenia ${ }^{22}$ and the other studies did not limit the comorbidity or health status of participants and the participants were not restricted to adults at risk of fall.

The risk of bias of included studies was unclear or low. Fifteen $^{12-15} 22-24 \quad 26-33$ and 13 trials ${ }^{12-15} 22 \quad 23 \quad 2627 \quad 29-33$ were considered at low risk in terms of random sequence generation and allocation concealment, respectively. Blinding of participants and personnel was adequate in seven studies, ${ }^{12} 27283032-34$ and blinding of outcome assessment was adequate in 14 studies. $^{12} \quad 14 \quad 15 \quad 22-24 \quad 26-28 \quad 30-34$ The risk of incomplete outcome data and selective reporting was low in $13^{12-15}$

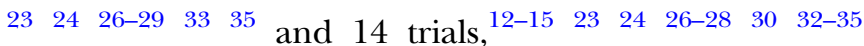
respectively. The detailed assessment of risk of bias was presented in online supplementary table S2.

\section{Number of fallers}

Sixteen studies (3539 participants) were included in the meta-analysis of the number of fallers (figure 2). The chance of falling at least once was significantly lower in the Tai Chi group than the control group (RR 0.80, 95\% CI 0.72 to 0.88 ; heterogeneity: $\left.\mathrm{p}=0.1, \mathrm{I}^{2}=32 \%\right)$. Overall, $10(95 \%$ CI 7 to 17$)$ older adults would need to take Tai Chi exercise to avoid one fall.

In the subgroup analysis by Tai Chi exercise frequency, total Tai Chi exercise time, time of follow-up, baseline falling risk and the style of Tai Chi, the chance of falling at least once was still lower in the Tai Chi group compared to the control group. Owing to reduced sample size, the RRs in some subgroups were not significant (table 2). The reduction in the risk seems to be larger in participants taking Yang style Tai Chi (RR $0.61,95 \%$ CI 0.46 to 0.80 ) than Sun style Tai Chi (RR 0.88, 95\% CI 0.80 to 0.98 ) (test for subgroup difference: $\mathrm{p}=0.01)$. Moreover, the effect size of Tai Chi seems to increase with exercise frequency $(\mathrm{p}=0.001)$, from an RR of 0.95 for once a week to 0.36 for $>3$ times a week.
Figure 1 Flow chart of study selection.

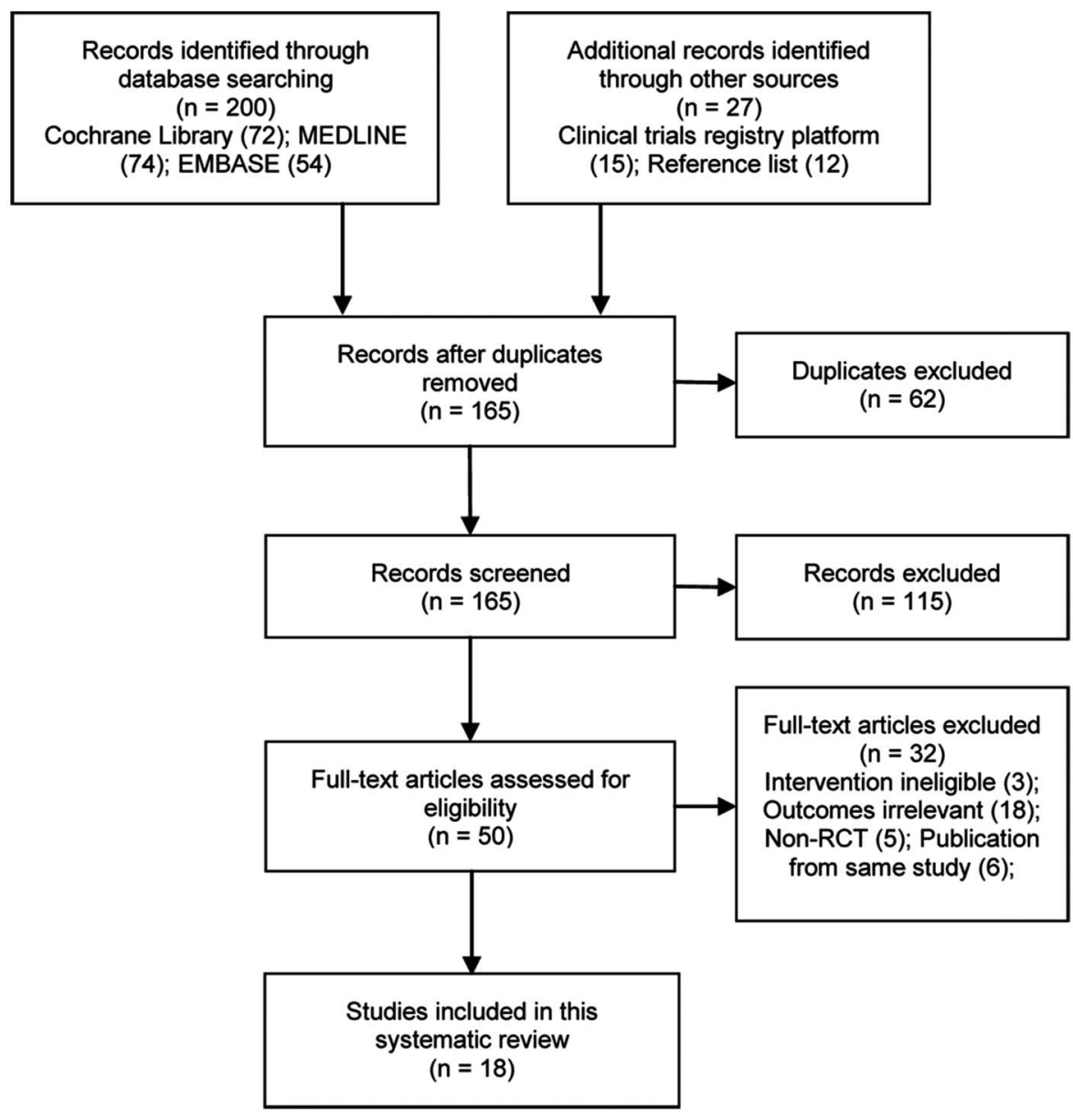


Table 1 Characteristics of included studies (arranged in order by publication time)

\begin{tabular}{|c|c|c|c|c|c|c|}
\hline Study & Intervention and control (n) & Tai Chi intensity & $\begin{array}{l}\text { Mean } \\
\text { age. } \\
\text { year }\end{array}$ & $\begin{array}{l}\text { Sex } \\
\text { F/M }\end{array}$ & $\begin{array}{l}\text { Falling } \\
\text { history, n } \\
(\%)\end{array}$ & $\begin{array}{l}\text { Follow-up } \\
\text { time }\end{array}$ \\
\hline Nowalk & Living and learning/Tai Chi (38) & Three times per week & 82.8 & $8 / 30$ & - & 24 months \\
\hline $2001^{29}$ & Basic enhanced programme (35) & for 24 months & 85.9 & $5 / 30$ & - & \\
\hline \multirow[t]{2}{*}{ Wolf $2003^{34}$} & Tai Chi (145) & Twice a week for & 80.9 & $137 / 8$ & - & 48 weeks \\
\hline & Wellness education (141) & 48 weeks & 80.8 & $132 / 9$ & - & \\
\hline \multirow[t]{2}{*}{ Li $2005^{14}$} & Yang-style Tai Chi (125) & Three sessions per & 76.9 & $87 / 38$ & - & 6 months \\
\hline & Stretching (131) & week for 26 weeks & 78 & $92 / 39$ & - & \\
\hline \multirow[t]{2}{*}{ Faber $2006^{12}$} & Tai Chi (80) & Once a week for & 84.8 & $61 / 19$ & - & 16 weeks \\
\hline & $\begin{array}{l}\text { Control, the participants were } \\
\text { asked not to change their usual } \\
\text { pattern of activities (66) }\end{array}$ & $\begin{array}{l}4 \text { weeks, followed by } \\
\text { twice weekly for } \\
16 \text { weeks }\end{array}$ & 85.4 & $53 / 13$ & - & \\
\hline \multirow[t]{2}{*}{$\begin{array}{l}\text { Voukelatos } \\
2007^{33}\end{array}$} & Sun or Yang-style Tai Chi (353) & $\begin{array}{l}\text { Once a week for } \\
16 \text { weeks }\end{array}$ & 69 & $\begin{array}{l}300 / \\
53\end{array}$ & $109(31 \%)$ & 16 weeks \\
\hline & No Tai Chi (349) & & 69 & $\begin{array}{l}290 / \\
59\end{array}$ & $126(36 \%)$ & \\
\hline \multirow[t]{2}{*}{ Woo $2007^{13}$} & Yang-style Tai Chi (60) & Three times per week & 68.9 & $30 / 30$ & - & 12 months \\
\hline & No Tai Chi (60) & for 12 months & 68.6 & $30 / 30$ & - & \\
\hline Logghe & Yang-style Tai Chi (138) & Twice a week for & 77.5 & $96 / 42$ & $88(63.8 \%)$ & 12 months \\
\hline $2009^{28}$ & Usual care (131) & 13 weeks & 76.8 & $95 / 36$ & $79(60.3 \%)$ & \\
\hline \multirow[t]{2}{*}{ Zeng $2009^{35}$} & Yang-style Tai Chi (63) & $\geq$ Three times a week & - & $98 / 26$ & $11(17.4 \%)$ & 2 years \\
\hline & No Tai Chi (61) & for 2 years & & & $12(19.7 \%)$ & \\
\hline \multirow[t]{2}{*}{ Chyu $2010^{22}$} & Yang-style Tai Chi (31) & Once a week for & 72.4 & $31 / 0$ & - & 24 weeks \\
\hline & No Tai Chi exercise (31) & 24 weeks & 71.3 & $31 / 0$ & - & \\
\hline Huang & Tai Chi (31) & Three sessions per & 71.4 & $9 / 22$ & - & 1 year \\
\hline $2010^{25}$ & No Tai Chi (47) & week for over 5 months & 71.5 & $19 / 28$ & - & \\
\hline Huang & Yang-style Tai Chi (62) & Five times a week for & - & $40 / 22$ & $12(10 \%)$ & 6 months \\
\hline $2011^{26}$ & No Tai Chi (62) & 8 weeks & - & $35 / 27$ & $12(12 \%)$ & \\
\hline \multirow[t]{2}{*}{ Li $2012^{27}$} & Tai Chi (65) & Twice a week for & 68 & $20 / 45$ & - & 24 weeks \\
\hline & Low-intensity exercise (65) & 24 weeks & 69 & $26 / 65$ & - & \\
\hline \multirow[t]{3}{*}{$\begin{array}{l}\text { Taylor } \\
2012 \mathrm{a}^{30}\end{array}$} & Sun-style Tai Chi (233) & $\begin{array}{l}\text { Once/twice a week for } \\
20 \text { weeks }\end{array}$ & 75.3 & $\begin{array}{l}161 / \\
72\end{array}$ & $137(60 \%)$ & 20 weeks \\
\hline & Sun-style Tai Chi (220) & & 74.4 & $\begin{array}{l}165 / \\
55\end{array}$ & $119(56 \%)$ & \\
\hline & Low-level exercise (231) & & 73.7 & $\begin{array}{l}176 / \\
55\end{array}$ & $137(61 \%)$ & \\
\hline Taylor & Yang-style Tai Chi (16) & Three sessions per & 72.8 & $6 / 10$ & - & 12 weeks \\
\hline $2012^{31}$ & Usual care (12) & week for 12 weeks & 64.5 & $5 / 7$ & - & \\
\hline Tousignant & Tai Chi (76) & Twice a week for & 79.1 & $57 / 19$ & $76(100 \%)$ & 12 months \\
\hline $2013^{32}$ & Conventional physical therapy (76) & 15 weeks & 80.7 & $54 / 22$ & $76(100 \%)$ & \\
\hline \multirow[t]{2}{*}{ Gao $2014^{24}$} & Yang-style Tai Chi+usual care (40) & Three sessions per & 69.5 & $14 / 23$ & - & 12 months \\
\hline & Usual care $(40)$ & week for 12 weeks & 68.3 & $12 / 27$ & - & \\
\hline Taylor & Yang-style Tai Chi (53) & Three sessions per & 71.5 & $19 / 34$ & - & 12 weeks \\
\hline $2014^{15}$ & $\begin{array}{l}\text { Usual community-based exercise } \\
\text { (48) }\end{array}$ & week for 12 weeks & 68.2 & $25 / 23$ & - & \\
\hline \multirow[t]{2}{*}{ Day $2015^{23}$} & Sun-style Tai Chi (205) & $\begin{array}{l}\text { Twice a week for } \\
48 \text { weeks }\end{array}$ & 77.6 & $\begin{array}{l}142 / \\
62\end{array}$ & $59(28.9 \%)$ & 48 weeks \\
\hline & Stretching (204) & & 77.8 & $\begin{array}{l}143 / \\
62\end{array}$ & $61(29.8 \%)$ & \\
\hline
\end{tabular}

Rate of falls

Fifteen studies including 3470 events contributed to the meta-analysis of the rate of falls (figure 3). Tai Chi exercise significantly reduced the rate of falls compared to the control (IRR 0.69, 95\% CI 0.60 to 0.80 ; heterogeneity: $\mathrm{p}=0.003, \mathrm{I}^{2}=57 \%$ ). The participants in the Tai Chi group were generally associated with lower rate of falls in various subgroups, though the IRRs might not always be significant as the sample sizes were reduced (table 2). Like the subgroup analyses for the number of fallers, subgroup analyses suggested that the size of estimated preventive effect in the Yang style Tai Chi group was larger than that in the Sun style Tai Chi group $(\mathrm{p}=0.001)$, and increased with Tai Chi exercise 
Tai Chi Control Risk Ratio

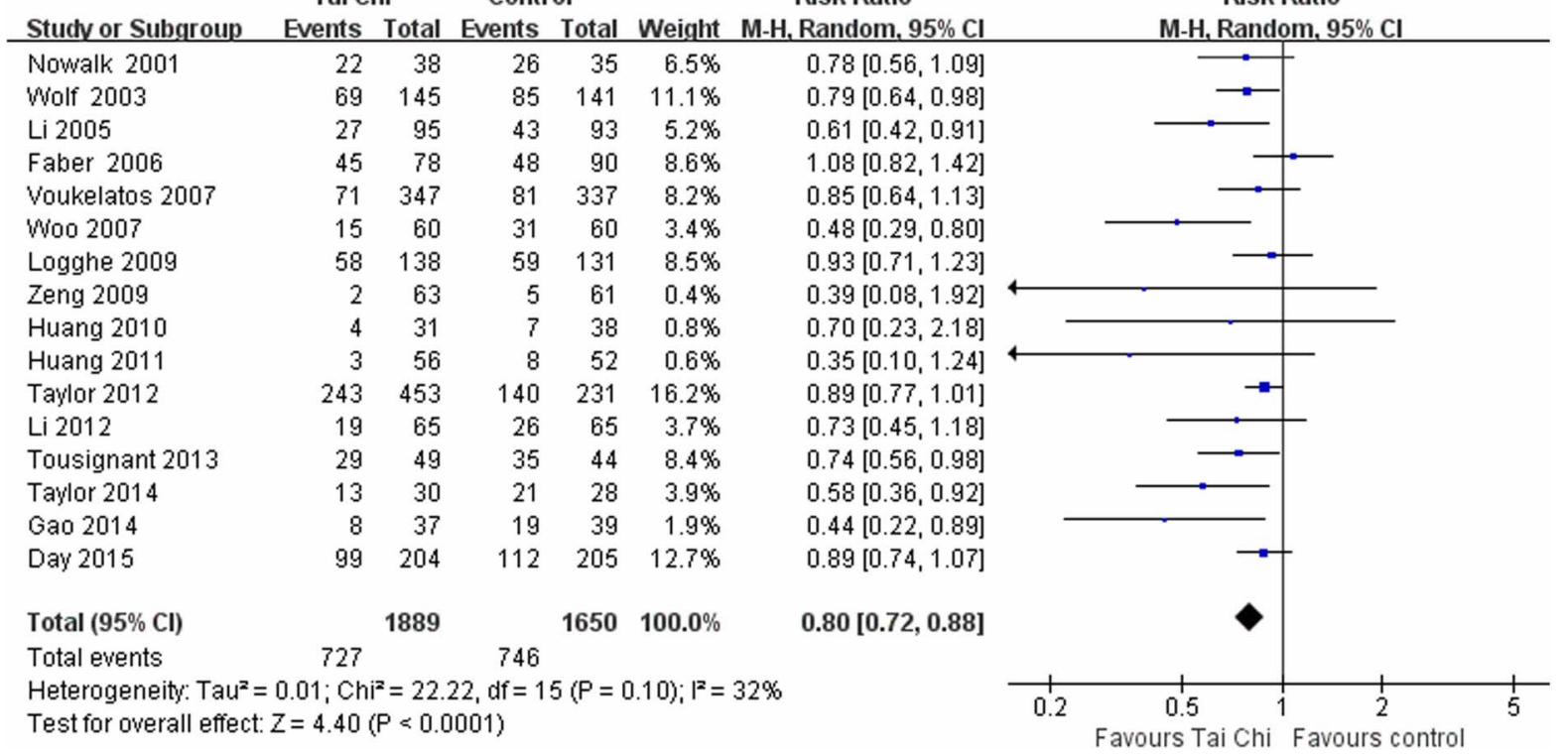

Table 2 Subgroup analyses of the effect of Tai Chi for preventing falls in older adults

\begin{tabular}{|c|c|c|c|c|c|c|}
\hline \multirow[b]{2}{*}{ Subgroup } & \multicolumn{3}{|l|}{ Number of fallers } & \multicolumn{3}{|l|}{ Rate of falls } \\
\hline & Studies & Participants & RR (95\% CI) & Studies & Falls & IRR (95\% CI) \\
\hline \multicolumn{7}{|c|}{ The style of Tai Chi } \\
\hline $\begin{array}{l}\text { Yang style } \\
\text { Tai Chi }\end{array}$ & $7^{13-1524262835}$ & 943 & 0.61 (0.46 to 0.80$)$ & $8^{13-152224262835}$ & 528 & $0.54(0.42$ to 0.70$)$ \\
\hline $\begin{array}{l}\text { Sun style Tai } \\
\text { Chi }\end{array}$ & $3^{233033}$ & 1777 & $0.88(0.80,0.98)$ & $3^{233033}$ & 1684 & $0.91(0.75$ to 1.11$)$ \\
\hline \multicolumn{4}{|c|}{ Test for subgroup differences: $p=0.01$} & \multicolumn{3}{|c|}{ Test for subgroup differences: $p=0.001$} \\
\hline \multicolumn{7}{|l|}{ Tai Chi frequency } \\
\hline Once a week & $3^{123033}$ & 1316 & $0.95(0.84$ to 1.07$)$ & $4^{12223033}$ & 1294 & $0.84(0.63$ to 1.13$)$ \\
\hline Twice a week & $6^{232728303234}$ & 1638 & $0.83(0.76$ to 0.92$)$ & $6^{232728303234}$ & 1641 & $0.73(0.57$ to 0.95$)$ \\
\hline $\begin{array}{l}\text { Three times a } \\
\text { week }\end{array}$ & $6^{13-15242529}$ & 584 & $0.62(0.51$ to 0.75$)$ & $4^{13-1524}$ & 454 & $0,48(0.36$ to 0.64$)$ \\
\hline $\begin{array}{l}\text { > Three times } \\
\text { a week }\end{array}$ & $2^{2635}$ & 232 & 0.36 (0.13 to 0.98$)$ & $2^{2635}$ & 81 & $0.38(0.18$ to 0.65$)$ \\
\hline Test for subgrou & differences: $p=0.001$ & & & Test for subgroup diffe & rences: & $p=0.07$ \\
\hline \multicolumn{7}{|c|}{ Total exercise time } \\
\hline$\leq 30$ hours & $5^{24} 28303233$ & 1586 & $0.85(0.73$ to 0.99$)$ & $5^{2428303233}$ & 1498 & $0.84(0.67$ to 1.07$)$ \\
\hline $\begin{array}{l}>30 \text { and } \leq 60 \\
\text { hours }\end{array}$ & $6^{122526283032}$ & 984 & $0.81(0.65$ to 1.00$)$ & $5^{1224283032}$ & 1138 & $0.58(0.35$ to 0.94$)$ \\
\hline$>60$ hours & $4^{14233435}$ & 1007 & 0.80 (0.67 to 0.94$)$ & $5^{1422} 233435$ & 437 & $0.64(0.49$, to 0.84$)$ \\
\hline \multicolumn{4}{|c|}{ Test for subgroup differences: $p=0.82$} & \multicolumn{3}{|c|}{ Test for subgroup differences: $p=0.20$} \\
\hline \multicolumn{7}{|c|}{ Time of follow-up } \\
\hline $\begin{array}{l}>1 \text { and } \\
\leq 3 \text { months }\end{array}$ & $4^{15242633}$ & 926 & $0.63(0.44$ to 0.89$)$ & $5^{1524262733}$ & 478 & $0.46(0.30$ to 0.69$)$ \\
\hline $\begin{array}{l}>3 \text { and } \\
<6 \text { months }\end{array}$ & $4^{14232733}$ & 1411 & $0.79(0.65$ to 0.94$)$ & $4^{14232733}$ & 633 & $0.67(0.52$ to 0.86$)$ \\
\hline $\begin{array}{l}>6 \text { and } \\
\leq 12 \text { months }\end{array}$ & $\begin{array}{l}10^{12} 13232528-30 \\
323435\end{array}$ & 2526 & $0.85(0.78$ to 0.93$)$ & $8^{1213232830323435}$ & 2633 & $0.85(0.73$ to 0.98$)$ \\
\hline \multicolumn{4}{|c|}{ Test for subgroup differences: $p=0.23$} & \multicolumn{3}{|c|}{ Test for subgroup differences: $p=0.01$} \\
\hline \multicolumn{7}{|c|}{ Falling risk at enrolment } \\
\hline High & $4^{24283032}$ & 1122 & $0.83(0.70$ to 0.98$)$ & $4^{24283032}$ & 1934 & $0.90(0.75$ to 1.07$)$ \\
\hline Low & $\begin{array}{l}12^{12-15} 2325-27 \\
2933-35\end{array}$ & 2417 & $0.78(0.68$ to 0.89$)$ & $\begin{array}{l}11^{12-15} 23262729 \\
33-35\end{array}$ & 1536 & $0.62(0.50$ to 0.76$)$ \\
\hline \multicolumn{4}{|c|}{ Test for subgroup differences: $p=0.57$} & \multicolumn{3}{|c|}{ Test for subgroup differences: $p=0.02$} \\
\hline
\end{tabular}




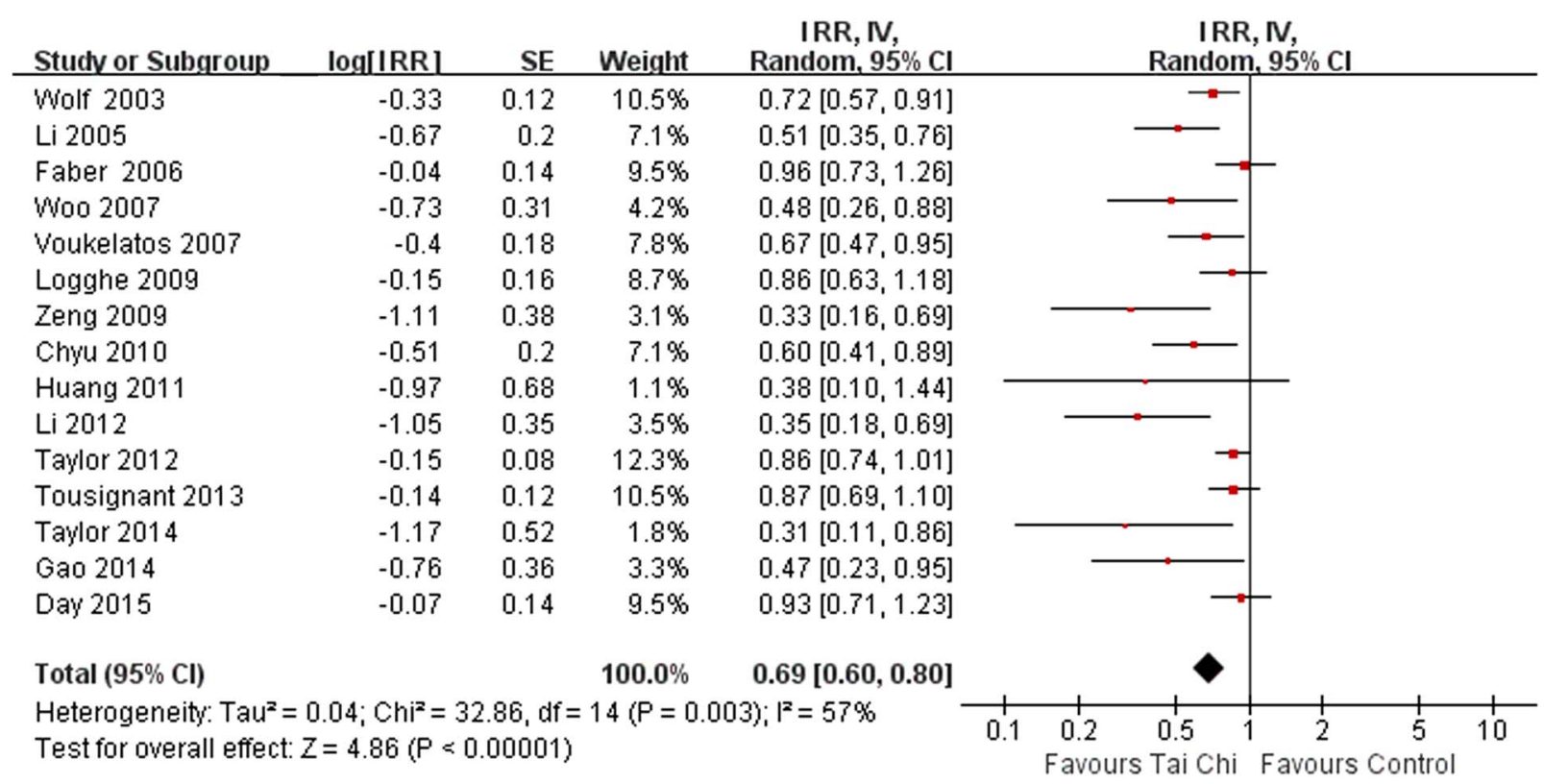

Figure 3 Meta-analysis of the rate of falls between the Tai Chi group and the control group. IRR, incidence rate ratio.
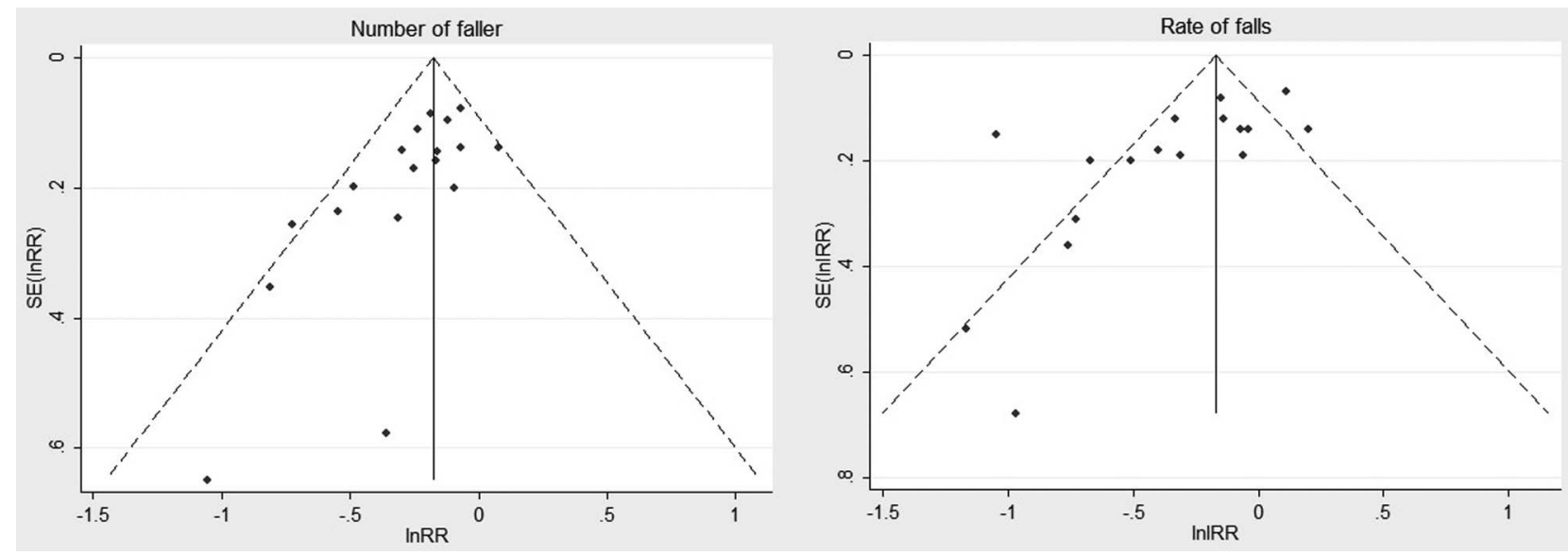

Figure 4 Evaluation of publication bias. RR, risk ratio; IRR, incidence rate ratio. The funnel plots showed asymmetry (there were no dots in the lower-right corner, which stand for small studies with small or negative effect), suggesting that the results were likely to be overestimated.

frequency $(p=0.007)$. Moreover, the preventive effect of Tai Chi was likely to reduce with follow-up time $(\mathrm{p}=0.002)$ and in participants with higher falling risk $(\mathrm{p}=0.02)$.

\section{Reporting bias and sensitivity analyses}

Funnel plots (figure 4) and Egger's tests (number of fallers: $p=0.005$; rate of falls: $p<0.001$ ) suggested that the meta-analyses were likely to be influenced by publication bias. We used the trim and fill method to adjust publication bias. However, no study was trimmed and the combined results were unchanged, suggesting that the weighting of the small studies with large effect was very low and the potential influence was minor. Sensitivity analyses by sample size, risk of bias and comorbidity did not show any major influence on the primary meta-analysis results (table 3 ).

\section{DISCUSSION}

Though a number of original trials and secondary studies have been performed to investigate the effect of Tai Chi for preventing falls in older adults, the evidence remains controversial. On the basis of 18 RCTs including 3824 participants, this systematic review indicated that Tai Chi significantly reduced the number of fallers (by $20 \%$ ) and the rate of falls (by 31\%). In addition, the effect of Yang style Tai Chi versus control was likely to be larger than the effect of Sun style Tai Chi versus control. Moreover, the preventive effect of Tai Chi was likely to increase with exercise frequency. 
Table 3 Sensitivity analyses by sample size, risk of bias and comorbidity

\begin{tabular}{|c|c|c|c|c|}
\hline & $\begin{array}{l}\text { Study removed from } \\
\text { the primary meta-analysis }\end{array}$ & $\begin{array}{l}\text { Number of } \\
\text { included studies }\end{array}$ & RR/IRR (95\% CI) & Heterogeneity* \\
\hline \multicolumn{5}{|l|}{ Sample size } \\
\hline Number of fallers & $5^{2224252930}$ & 11 & $0.83(0.74$ to 0.93$)$ & \multirow{2}{*}{$\begin{array}{l}p=0.12 ; I^{2}=35 \% \\
p=0.003 ; I^{2}=62 \%\end{array}$} \\
\hline Rate of falls & $4^{22242530}$ & 11 & 0.69 (0.57 to 0.83$)$ & \\
\hline \multicolumn{5}{|l|}{ Risk of bias } \\
\hline Number of fallers & $6^{252930323435}$ & 10 & $0.76(0.64$ to 0.90$)$ & \multirow{2}{*}{$\begin{array}{l}p=0.02 ; I^{2}=54 \% \\
p=0.007 ; I^{2}=60 \%\end{array}$} \\
\hline Rate of falls & $5^{2530323435}$ & 10 & 0.65 (0.53 to 0.81$)$ & \\
\hline \multicolumn{5}{|l|}{ Comorbidity } \\
\hline Number of fallers & $4^{14152431}$ & 12 & $0.83(0.74$ to 0.92$)$ & \multirow{2}{*}{$\begin{array}{l}p=0.27 ; 1^{2}=18 \% \\
p=0.02 ; 1^{2}=54 \%\end{array}$} \\
\hline Rate of falls & $4^{14152431}$ & 11 & $0.72(0.61$ to 0.85$)$ & \\
\hline
\end{tabular}

A previous meta-analysis of 13 RCTs have indicated that Tai Chi was effective in improving balance and reducing falls in the non-frail elderly. ${ }^{17}$ The finding was consistent with a recently published meta-analysis of six trials, which excluded the studies recruiting participants who had a degenerative neurological condition, severe arthritis or marked vision impairments. ${ }^{18}$ To the contrary, the study by Logghe and colleagues suggested that there was insufficient evidence that Tai Chi reduced the incidence of falls. ${ }^{16} \mathrm{~A}$ possible explanation is that some recently published trials ${ }^{15} 23242730-32$ were not included so the power of the test was low. Compared with previous meta-analyses, the present study did not limit the comorbidity of participants, included recently published trials and investigated various factors that may influence the preventive effect, therefore provided more comprehensive evidence for practice.

To date few studies have been carried out to investigate the intensity of Tai Chi and the preventive effect. In the study by Taylor et $a l,{ }^{30}$ Tai Chi once a week and twice a week was compared with low-level exercise for 20 weeks; the results suggested that the number of fallers was relatively lower in the twice per week group $(53.4 \%)$ than the once per week group $(59.5 \%)$ though the difference was not significant. Though based on subgroup analyses which may be confounded with other study-level factors, our results showed a clear trend that increase in Tai Chi exercise frequency was associated with a significant increase in the preventive effect, in terms of number of fallers and rate of falls.

An important strength of this study is that a comprehensive literature search was performed and many recently published trials were included. ${ }^{15} \quad \begin{array}{lllll}23 & 24 & 31 & 32\end{array}$ These studies greatly improved the precision of the estimated effect and enabled us to investigate various influential factors like Tai Chi style and frequency. In addition, for all the prespecified sensitivity analyses, the results had very small difference as compared with the primary results, indicating that the primary results were robust and further actions to resolve the difference was not needed. Our confidence in the findings is further increased by significant dose-response effect and stable analyses by adjusting for publication bias.
It should be noticed that the results are likely to be influenced due the potential bias in some original trials. Like many other trials evaluating exercise intervention, blinding of participants was hard to implement; however, the potential influence would be minor as the end points of this systematic review was unlikely to be affected. The sensitivity analyses by the risk of bias also showed no major influence to the primary analysis results. In addition, clinical heterogeneity in comorbidity, living status, education status, alcohol consumption and use of walking aids may affect the meta-analysis results, but we were unable to investigate these factors as individual patient data were not available. Finally, the estimated preventive effect of Tai Chi may be overestimated due to publication bias. However, we adjusted the meta-analyses by the trim and fill method and the results were not changed, suggesting that the potential influence was minor. This was confirmed by the sensitivity analyses by removing the studies with a sample size $<100$.

Overall, Tai Chi exercise is effective for preventing falls in older adults. The preventive effect seems to increase with exercise frequency, and Yang style Tai Chi seems to be more effective than Sun style Tai Chi, though direct comparisons are lacking. Future studies are required to investigate the most effective intensity and style of Tai Chi exercise and to assess the effect in older adults with certain comorbidities, such as stroke and Parkinson's disease.

Contributors $\mathrm{Y}-\mathrm{HF}$ and $\mathrm{Y}-\mathrm{HL}$ contributed to conception and design and manuscript revision. Z-GH and Y-HF contributed to selection and screening of trials included in this meta-analysis. Z-GH and C-SL contributed to data extraction and risk of bias assessment. Z-GH, C-SL and Y-HL contributed to data analysis. Z-GH and C-SL involved in writing of the paper.

Funding This study was funded by Guangdong Outstanding Young Teacher Training Program in Higher School (YQ2015104) and Science and Technology Plan Projects of Guangdong Province (2013B031600004).

Competing interests None declared.

Provenance and peer review Not commissioned; externally peer reviewed.

Data sharing statement No additional data are available.

Open Access This is an Open Access article distributed in accordance with the Creative Commons Attribution Non Commercial (CC BY-NC 4.0) license, 
which permits others to distribute, remix, adapt, build upon this work noncommercially, and license their derivative works on different terms, provided the original work is properly cited and the use is non-commercial. See: http:// creativecommons.org/licenses/by-nc/4.0/

\section{REFERENCES}

1. Rubenstein LZ. Falls in older people: epidemiology, risk factors and strategies for prevention. Age Ageing 2006;35(Suppl 2):ii37-41.

2. Rubenstein LZ, Josephson KR. The epidemiology of falls and syncope. Clin Geriatr Med 2002;18:141-58.

3. Gill TM, Murphy TE, Gahbauer EA, et al. Association of injurious falls with disability outcomes and nursing home admissions in community-living older persons. Am J Epidemiol 2013;178:418-25.

4. Tinetti ME, Williams CS. Falls, injuries due to falls, and the risk of admission to a nursing home. N Engl J Med 1997;337:1279-84.

5. Berry SD, Miller RR. Falls: epidemiology, pathophysiology, and relationship to fracture. Curr Osteoporos Rep 2008;6:149-54.

6. Kannus P, Parkkari J, Niemi S, et al. Fall-induced deaths among elderly people. Am J Public Health 2005;95:422-4.

7. Kenny RAM, Rubenstein LZ, Tinetti ME, et al. Summary of the updated American Geriatrics Society/British Geriatrics Society clinical practice guideline for prevention of falls in older persons. J Am Geriatr Soc 2011;59:148-57.

8. Falls: assessment and prevention of falls in older people. NICE clinical guideline 16. https:// http://www.nice.org.uk/guidance/cg161

9. Gillespie LD, Robertson MC, Gillespie WJ, et al. Interventions for preventing falls in older people living in the community. Cochrane Database Syst Rev 2012;(9):CD007146.

10. Jacobson $\mathrm{BH}$, Chen $\mathrm{HC}$, Cashel $\mathrm{C}$, et al. The effect of T'ai Chi Chuan training on balance, kinesthetic sense, and strength. Percept Mot Skills 1997;84:27-33.

11. Wang CC, Collet JP, Lau J. The effect of Tai Chi on health outcomes in patients with chronic conditions: a systematic review. Arch Intern Med 2004;164:493-501.

12. Faber MJ, Bosscher RJ, Chin A Paw MJ, et al. Effects of exercise programs on falls and mobility in frail and pre-frail older adults: a multicenter randomized controlled trial. Arch Phys Med Rehabil 2006;87:885-96.

13. Woo J, Hong A, Lau E, et al. A randomised controlled trial of Tai Ch and resistance exercise on bone health, muscle strength and balance in community-living elderly people. Age Ageing 2007;36:262-8.

14. Li F, Harmer P, Fisher KJ, et al. Tai Chi and fall reductions in older adults: a randomized controlled trial. J Gerontol A Biol Sci Med Sci 2005;60:187-94.

15. Taylor-Piliae RE, Hoke TM, Hepworth JT, et al. Effect of Tai Chi on physical function, fall rates and quality of life among older stroke survivors. Arch Phys Med Rehabil 2014;95:816-24.

16. Logghe IHJ, Verhagen AP, Rademaker ACHJ, et al. The effects of Tai Chi on fall prevention, fear of falling and balance in older people: a meta-analysis. Prev Med 2010;51:222-7.

17. Leung DPK, Chan CKL, Tsang HWH, et al. Tai Chi as an intervention to improve balance and reduce falls in older adults: a systematic and meta-analytical review. Altern Ther Health Med 2011;17:40-8.
18. Yuan Z, Yan W. Tai Chi as an intervention to reduce falls and improve balance function in the elderly: a meta-analysis of randomized controlled trials. Chin Nurs Res 2016;3:28-33.

19. Higgins J, Green S. Cochrane handbook for systematic reviews of interventions Version 5.1.0 (updated March 2011). The Cochrane Collaboration, 2011. http://www.cochrane-handbook.org.

20. Egger M, Davey Smith G, Schneider M, et al. Bias in meta-analysis detected by a simple, graphical test. BMJ 1997;315:629-34.

21. Duval S, Tweedie R. Trim and fill: a simple funnel-plot-based method of testing and adjusting for publication bias in meta-analysis. Biometrics 2000;56:455-63.

22. Chyu MC, James CR, Sawyer SF, et al. Effects of Tai Chi exercise on posturography, gait, physical function and quality of life in postmenopausal women with osteopaenia: a randomized clinical study. Clin Rehabil 2010;24:1080-90.

23. Day L, Hill KD, Stathakis VZ, et al. Impact of Tai-Chi on falls among preclinically disabled older people. A randomized controlled trial. J Am Med Dir Assoc 2015;16:420-6.

24. Gao Q, Leung A, Yang Y, et al. Effects of Tai Chi on balance and fall prevention in Parkinson's disease: a randomized controlled trial. Clin Rehabil 2014;28:748-53.

25. Huang HC, Liu CY, Huang YT, et al. Community-based interventions to reduce falls among older adults in Taiwan-long time follow-up randomised controlled study. J Clin Nurs 2010;19:959-68.

26. Huang TT, Yang LH, Liu CY. Reducing the fear of falling among community-dwelling elderly adults through cognitive-behavioural strategies and intense Tai Chi exercise: a randomized controlled trial. J Adv Nurs 2011;67:961-71.

27. Li F, Harmer P, Fitzgerald K, et al. Tai Chi and postural stability in patients with Parkinson's disease. N Engl J Med 2012;366:511-19.

28. Logghe IH, Zeeuwe PE, Verhagen AP, et al. Lack of effect of Tai Ch Chuan in preventing falls in elderly people living at home: a randomized clinical trial. J Am Geriatr Soc 2009;57:70-5.

29. Nowalk MP, Prendergast JM, Bayles CM, et al. A randomized trial of exercise programs among older individuals living in two long-term care facilities: the FallsFREE program. J Am Geriatr Soc 2001:49:859-65.

30. Taylor D, Hale L, Schluter P, et al. Effectiveness of Tai Chi as a community-based falls prevention intervention: a randomized controlled trial. J Am Geriatr Soc 2012;60:841-8.

31. Taylor-Piliae RE, Coull BM. Community-based Yang-style Tai Chi is safe and feasible in chronic stroke: a pilot study. Clin Rehabil 2012;26:121-31.

32. Tousignant M, Corriveau H, Roy PM, et al. Efficacy of supervised Tai Chi exercises versus conventional physical therapy exercises in fall prevention for frail older adults: a randomized controlled trial. Disabil Rehabil 2013;35:1429-35.

33. Voukelatos A, Cumming RG, Lord SR, et al. A randomized, controlled trial of Tai Chi for the prevention of falls: the Central Sydney Tai Chi trial. J Am Geriatr Soc 2007;55:1185-91.

34. Wolf SL, Sattin RW, Kutner M, et al. Intense Tai Chi exercise training and fall occurrences in older, transitionally frail adults: a randomized controlled trial. J Am Geriatr Soc 2003;51:1693-701.

35. Zeng YH, Zhu HX, Liang GY, et al. The impact of Tai Chi for improve balance and reduce falls in older adults. The Tenth National Therapeutic Exercise Conference of Chinese Association of Rehabilitation Medicine, Chengdu, 2009. 